\title{
A militarização da infância: Expressões do nacionalismo na cultura brasileira
}

\author{
Rosa Fátima de Souza*
}

\begin{abstract}
RESUMO: O texto compreende um estudo sobre as práticas de militarização da infância, isto é, práticas de natureza patriótica, cívicomilitar que predominaram no ensino primário, no início do século XX. Nesse sentido, destaca a introdução da disciplina "Ginástica e exercícios militares" nos programas de ensino e seus desdobramentos mediante a criação dos Batalhões Infantis. Analisa, também, o escotismo escolar, movimento efervescente no estado de São Paulo nas décadas de 1910 e 1920, identificando-o como mais uma expressão do militarismo e do nacionalismo na educação brasileira. Para a realização deste estudo foram utilizadas fontes manuscritas encontradas no Arquivo do Estado de São Paulo e periódicos educacionais da época.
\end{abstract}

\section{Palavras-chave : História do currículo, história do ensino primário, cultura escolar, educação militar, escotismo escolar}

Este texto apresenta os resultados iniciais de uma investigação histórica sobre a cultura escolar configurada na escola primária paulista no período de 1892-1968. ${ }^{1}$ Esta pesquisa incide sobre a história das disciplinas do ensino primário e das práticas escolares de natureza cívico-patrióticas: os batalhões infantis, o escotismo escolar e as comemorações cívicas. O estudo busca verificar as formas pelas quais a escola primária contribuiu para a consolidação do projeto político-ideológico de construção da

* Professora Assistente Doutora - Departamento de Ciências da Educação - Faculdade de Ciências e Letras - Unesp - Campus de Araraquara. E-mail: rosa@fclar.unesp.br 
nacionalidade brasileira e objetiva examinar o papel do Estado em relação à inovação educacional e à imposição de modelos culturais.

O presente texto examina as práticas de militarização da infância, isto é, práticas de natureza patriótica, cívico-militar que predominaram na escola primária, no início do século XX. Nesse sentido, destaca a introdução da disciplina "Ginástica e exercícios militares" nos programas de ensino e seus desdobramentos mediante a criação dos Batalhões Infantis. Analisa, também, o escotismo escolar, movimento efervescente no estado de São Paulo nas décadas de 1910 e 1920, identificando-o como mais uma expressão do militarismo e do nacionalismo na educação brasileira. Para a realização deste estudo foram utilizadas fontes manuscritas encontradas no Arquivo do Estado de São Paulo e periódicos educacionais da época.

O projeto de pesquisa mencionado acima tem como referencial a interseção entre a História Cultural e a História do Currículo. Em relação à História Cultural, fundamenta-se nas obras de Chartier $(1989,1990)$ e Certeau (1982) buscando compreender, por um lado, a relação entre as representações e as práticas, além da eficácia simbólica do Estadoe, por outro, os mecanismos de circulação e apropriação de modelos culturais.

As tendências que emergem na História da Educação, filiadas às novas correntes historiográficas e à História Cultural, propõem um reexame das relações entre a educação e a cultura, indicando a necessidade de uma acurada atenção aos processos internos à escola, as práticas que consolidam uma determinada existência das instituições escolares e, não obstante, guardam intrínsecas relações com o universo social e cultural (Nóvoa 1994; Frago 1994).

É nesse sentido que adquire relevância a concepção de cultura escolar tal como a concebe Julia (1993), envolvendo saberes a ensinar, condutas a inculcar e um conjunto de práticas que permitem a transmissão de saberes, constituindo, pois, aspectos indicativos para uma história social do currículo. Em relação a esse campo de pesquisa destaca-se a contribuição de autores como Goodson (1995, 1997), Popkewitz (1997), Chervel (1990), Hébrard (1990) e Frago (1994).

\section{A (re)invenção da escola primária}

Nas últimas décadas do século XIX, a educação popular adquiriu centralidade política como nunca tivera antes no Brasil. Ela foi considerada 
o elemento de regeneração da nação, um instrumento para a reforma social e a propulsora do progresso e da civilização. A educação do povo compreendia, portanto, um amplo projeto político-social e uma bandeira de luta para monarquistas e conservadores, e, especialmente, para liberais e republicanos.

O advento da República em 1889 ratificou a crença no poder da educação popular, ressaltada, a partir de então, como instrumento de consolidação do novo regime político e de manutenção da ordem social. A educação do povo atendia a uma das condições para a participação política, uma vez que a República manteve a interdição ao voto do analfabeto, excluindo, assim, grande parte da população brasileira da cidadania política. Mais que um direito do cidadão, a escola primária foi concebida como uma necessidade e, sobretudo, como um dever de cada homem do povo. Diante da soberania popular, para o Estado, a educação configurava-se como um interesse em decorrência do qual sobressaia o rigoroso dever em promovê-la.

Essas novas finalidades atribuídas à escola primária vieram acompanhadas de profundas reformas no ensino público. No estado de São Paulo, o projeto republicano de educação popular abrangeu dois aspectos: a expansão da oferta de vagas mediante a criação de escolas públicas e a renovação educacional, faces de um mesmo processo político de modernização da sociedade. Tal renovação envolveu os programas de ensino, com a introdução de novas disciplinas e conteúdos culturais, a adoção de modernos métodos e processos pedagógicos, especialmente o método intuitivo ou "lições de coisas", o uso de abundante material didático e livros escolares e a implantação de uma nova modalidade de escola primária, denominada Grupos Escolares, adequada para a escolarização em massa e fundamentada nos princípios da racionalidade técnica e na divisão do trabalho.

A discussão sobre as matérias que deveriam compor os programas do ensino primário no Brasil esteve no centro dos debates educacionais a partir de 1870. O projeto cultural estabelecido no currículo da escola primária paulista, no início da República, permaneceu por várias décadas. Sem alterarem profundamente o projeto político-cultural do início da República, isto é, a formação do cidadão republicano alicerçada na ciência e nos valores morais e cívicos, as principais mudanças recaíram sobre o acréscimo ou a supressão de determinados conteúdos, sobre o detalhamento das instruções metodológicas e sobre a forma de organização dos conteúdos das 
matérias. ${ }^{2}$ As práticas de conteúdo cívico-militar também se transformaram nesse período, mantendo, não obstante, a ideologia patriótica e de construção da nacionalidade.

\section{Origem da educação militar nas escolas primárias paulistas}

A renovação dos programas do ensino primário foi defendida por Rui Barbosa em seu célebre Parecer sobre a Reforma do Ensino Primário e várias instituições complementares da instrução pública, datado de 1882. Em um volume específico destinado à questão do método e do programa de ensino, Rui Barbosa dedicou-se a demonstrar com minuciosa parcimônia persuasiva as vantagens de cada uma das matérias que deveriam compor o currículo enciclopédico da escola primária brasileira, isto é, Educação Física, Música e Canto, Desenho, Língua Materna, Rudimentos das Ciências Físicas e Naturais, Matemática, Geografia e Cosmografia, História, Rudimentos de Economia Política e Cultura Moral e Cívica.

Em relação à Educação Física, o republicano Rui Barbosa construiu seus argumentos com base no princípio da educação integral - educação física, intelectual e moral -, apelando para a indissociabilidade entre corpo e espírito e para a necessidade do processo educativo seguir as mesmas leis da natureza. ${ }^{4}$ Nas representações de Rui sobre os benefícios da Ginástica na educação popular, emergem as funções morais, cívicas, disciplinadoras e higiênicas que foram atribuídas a esse ensino no século XIX. ${ }^{5}$

A primeira reforma republicana da instrução pública paulista, realizada em 1892, estabeleceu um programa enciclopédico consoante aos ideais de renovação educacional predominantes na época, introduzindo várias disciplinas no programa de ensino, entre elas Ginástica e Exercícios Militares (ver Souza 1998).

Em 1894, foi estabelecido o regimento interno das escolas públicas do estado de São Paulo (Decreto 248, de 26/6/1894), trazendo, em anexo, o programa mais detalhado das matérias do ensino primário. No entanto, nenhuma indicação foi mencionada no programa em relação aos exercícios militares, demonstrando, assim, uma certa indefinição da diretoria da instrução pública acerca do desenvolvimento desse conteúdo escolar. Em realidade, coube aos periódicos educacionais oferecerem uma orientação aos professores. No início do século, a Revista de Ensino publicou vários 
artigos sobre a educação militar com base no livro Instruções para o Exército Brasileiro. No programa de 1905, esses exercícios compreendiam marchas, formaturas em filas e fileiras, evolução da companhia sem armas e com armas. O ensino de ginástica e exercícios militares fazia parte do currículo da Escola Normal de São Paulo, para os alunos do sexo masculino. No entanto, nessa escola predominavam alunos do sexo feminino; por isso, poucos professores primários estavam habilitados para o ensino da matéria. Por essa razão, vários grupos escolares contaram, no início do século XX, com o trabalho voluntário de soldados reformados do exército para o desenvolvimento dessa atividade. ${ }^{6}$

A prática dos exercícios militares gerou a formação dos batalhões infantis. ${ }^{7}$ Em 1904, eles foram regulamentados pelo regimento interno dos Grupos Escolares e Escolas-Modelo (Decreto 1.212, de 27/4/1904), concebidos como meio de estímulo aos alunos, de forma que os postos fossem distribuídos para aqueles que melhor se distinguissem por seu comportamento, aplicação e garbo militar. Nos batalhões dever-se-ia aplicar o regime militar como meio profícuo de disciplina.

Os batalhões, simulacros de corporações militares, recebiam treinamento fora do horário regulamentar das aulas e utilizavam um aparato condizente com o ritual cívico a que se prestavam: além do fardamento, espingardas de madeira, cinturões, baionetas, tambores e cornetas. Cada batalhão possuía um estandarte e recebia o nome de um herói nacional ou de uma personagem política eminente. À semelhança das organizações militares, os batalhões infantis, reunindo pequenos soldados, simbolizavam uma das finalidades primordiais da escola pública: a celebração cívica. Nesse sentido, eles contribuíram não apenas para a "invenção das tradições" conforme sugerem Hobsbawm e Ranger (1997), participando das comemorações cívicas - as festas nacionais instituidoras de uma memória nacional -, como ajudaram a reforçar o imaginário sociopolítico da República. Entende-se, dessa forma, o encantamento que tais agremiações provocavam na sociedade da época ao oferecerem a representação de um corpo unido e harmônico, como deveria ser a pátria e a nova ordem. Ao desfilarem pelas ruas da cidade, manifestavam todo o sentido simbólico da escola no meio social.

Desde o início, o ensino militar enfrentou vários problemas, entre eles a falta de uniformidade. Cada instrutor utilizava um sistema de instrução, cada escola usava um uniforme diferente e diversos materiais didáticos. Nas representações de alguns educadores da época, a educação militar 
possuía finalidades que incluíam o sentimento de patriotismo, o desenvolvimento das virtudes cívicas, a moralização dos hábitos, a eugenia e a disciplina corporal.

Por volta da Primeira Guerra Mundial, os exercícios militares entraram em franca decadência. Muitas escolas primárias haviam abolido por completo a sua prática, mantendo apenas a ginástica. Os batalhões escolares eram criticados em vários países da América Latina como se pode observar no relatório do inspetor de ensino Mário Cardin: "seja-nos permitido fazer aqui algumas observações, a propósito dos chamados batalhões escolares que foram abolidos por completo na nova organização que a Argentina e o Uruguai adotaram para a cultura física da sua juventude, seguindo o exemplo dos países mais adiantados" (Anuário do Ensino do Estado de São Paulo, 1918, p. 189). Mesmo antes da Primeira Guerra, muitos países vinham condenando qualquer ensino ou preparo de natureza militar antes dos 19 anos, fosse do ponto de vista higiênico, quanto da cultura física e moral. Conforme afirmava o inspetor, a Inglaterra havia substituído os exercícios militares pelo desporto. A questão vinha sendo discutida na Alemanha, na França e na Argentina. Em vez de exercícios militares, o inspetor sugeria o escotismo: "o que se não fez na Argentina nem no Uruguai mas está sendo praticado com grandes resultados em todos os países é substituir esses decaídos batalhões escolares pelos agrupamentos de escoteiros (ibidem, p. 191).

Os exercícios militares e os batalhões infantis estavam fadados ao esquecimento, mas não o espírito militar inspirador da educação física, moral e cívica que viria a se firmar durante muitas décadas na escola paulista mediante a prática do escotismo.

\section{Escotismo: Escola de moral e civismo}

Após a Primeira Guerra Mundial, o Brasil viveu uma onda de nacionalismo efervescente. Vários movimentos e campanhas nacionalistas eclodiram, tendo como finalidade a elevação moral e política do país e como principais temas o voto secreto, a erradicação do analfabetismo e o serviço militar obrigatório. O fervor nacionalista, alimentado por alguns grupos políticos e intelectuais descontentes com a oligarquia no poder e os desvirtuamentos da República, trouxe à baila a questão da nacionalidade brasileira, o combate à estrangeirização do Brasil, a reforma política, a moralização 
dos costumes e a regeneração da nação. Era preciso "republicanizar a República" e a educação foi novamente apontada como a solução destes e de todos os males do país (Nagle 1990).

Juntamente com a erradicação do analfabetismo, questão política de ampliação das bases eleitorais, grande ênfase foi dada à educação cívica, considerada elemento fundamental para o soerguimento moral da nação, para a cultura do patriotismo e para a defesa da nacionalidade. É nesse contexto que surge e se intensifica nos meios educacionais e políticos a defesa do escotismo como fator de educação do caráter e de defesa da pátria. ${ }^{8}$ Em 1916, o professor Amadeu Amaral referia-se ao escotismo como "maravilhoso processo para a remodelação moral de um povo" (Revista de Ensino, 1916, n. 1, p. 14). De acordo com os estatutos e regulamentos da Associação Brasileira de Escoteiros, o escotismo tinha por objetivo:

1ํ- Eugenia, na parte referente à educação física, à saúde, ao vigor e à destreza das gerações novas, homens e mulheres;

2ํ- Civismo, não apenas reduzido a ensinamentos cívicos, mas o hábito de realizar os deveres cívicos, mercê das convicções adquiridas;

3-ㅡㄴ Inteligência, isto é, o desenvolvimento de algumas das mais notáveis qualidades intelectuais, a urgência, a logicidade, a divisão pronta;

4ํ- Caráter, considerado como o hábito adquirido pela prática sistemática da bondade, em casos concretos, dia a dia, como o horror à mentira e correlato amor à verdade, à pontualidade. (Campos 1922, p. 7)

Foi essa associação entre educação cívica e nacionalismo que facultou o entusiasmo pelo escotismo e a sua implantação em massa na instrução pública paulista, fato de grande relevância para se compreender o surgimento de determinadas práticas escolares e suas dimensões simbólicas.

De fato, a defesa do escotismo escolar ocorreu, também, fora dos círculos educacionais sendo propagado especialmente por organizações políticas. Fazia parte, por exemplo, da plataforma da Liga de Defesa Nacional fundada no Rio de Janeiro em 1916:

(...) manter a idéia de coesão nacional, defender o trabalho nacional, difundir a instrução militar nas diversas instituições, desenvolver o 
civismo, o culto ao heroísmo, fundar associações de escoteiros, linhas de tiro e batalhões patrióticos, arrivar o estudo da História do Brasil e das tradições brasileiras, promover o ensino da língua pátria nas escolas estrangeiras existentes no país; propagar a educação popular e profissional, difundir nas escolas o amor à justiça e o culto ao patriotismo; combater o analfabetismo (Nagle 1974, p. 331).

Encontrava-se, ainda, nos estatutos da Liga Nacionalista de São Paulo, criada em 1917, que se propunha a "combater a abstenção eleitoral bem como todas as fraudes que corrompem e viciam o exercício do voto" (apud Nagle 1990, p. 263) e empreender "a educação física do cidadão, o escotismo, as linhas de tiro e o preparo militar" (Boto 1990, p. 229).

A administração do ensino no estado de São Paulo assumiu prontamente a implementação do escotismo nas escolas públicas. Em 1917, a Diretoria do Ensino entrou em entendimento com a Associação Brasileira de Escoteiros para viabilizar esse fim (Anuário do Ensino do Estado de São Paulo, 1917, p. 97). Em um dos salões da Diretoria foi aberto um curso de escotismo para os inspetores e diretores de grupos escolares com a colaboração de Mário Cardin e do coronel Pedro Dias de Campos. Para acelerar a introdução do escotismo nas escolas primárias foi expedida uma circular para os diretores recomendando a organização imediata das comissões distritais de escoteiros, que deveriam ser compostas pelo diretor do grupo escolar, por professores e pessoas da comunidade. Organizada a comissão, o presidente deveria, por intermédio do diretor geral do ensino, enviar um oficio à Associação Brasileira de Escoteiros, comunicando-Ihe a instalação e o funcionamento da agremiação a fim de ser considerada entre as filiais.

Nascia, assim, o escotismo escolar, vinculado ao movimento nacionalista e patrocinado pela ação do Estado. A estrutura organizacional e hierárquica subordinava o escotismo escolar à Associação Brasileira de Escoteiros, que indicava a orientação técnica contida no Manual de Escoteiros, estabelecia programas de atividades para os diferentes níveis ou classes de escoteiros, prescrevia o fardamento e centralizava toda a organização técnica e administrativa.

A adoção do escotismo nas escolas públicas enfrentou algumas dificuldades. Para os inspetores de ensino, o maior problema era a falta de orientação pedagógica: "para ser escoteiro não é somente necessário conhecer de cor o respectivo código, é necessário que o candidato se sujeite 
às medidas autopunitivas, que passe por um exame médico meticuloso, principalmente do aparelho respiratório e do circulatório, que os exercícios sejam em ordem crescente de dificuldades" (Anuário do Ensino do Estado de São Paulo, 1918, p. 294). Além desse problema, o Anuário notificava ocorrências na Escola-Modelo que denegriam a imagem do escotismo e colocavam em questão as suas vantagens. Nessa escola, os monitores aplicavam castigos depreciativos do caráter e promoviam paradas demoradas, mantendo crianças de oito, nove e dez anos muito tempo sob o sol. Na capital, as reuniões eram marcadas na Praça da República, às 7 horas da manhã e terminavam às 15 horas, e nesse período as crianças nem se alimentavam.

\begin{abstract}
Esses fatos que acabamos de expor concorrem para implantar a descrença nos fins a que se propõe a benemérita instituição e a dedicação e propaganda dos diretores de estabelecimentos de ensino caem por terra, em vista da resistência oposta pelos pais, que desconfiam das verdades proclamadas em vista dos fatos que observam.
\end{abstract}

Somos, pois, de opinião que só uma orientação pedagógica ditada pelos competentes pode medrar, com resultados satisfatórios, a magnífica instituição que será capaz de elevar o prestígio de nosso valor físico e de nossa resistência moral. (ibidem)

Mas no início da década de 1920, a educação militar se revitalizou no estado de São Paulo, mediante a introdução obrigatória nos currículos escolares do escotismo e da linha de tiro. Essa medida foi tomada no interior da reforma da instrução pública realizada em 1920 sob a liderança do professor Sampaio Dória, membro atuante da Liga Nacionalista de São Paulo.

De acordo com o Decreto 3.355, de 27/5/1921, que regulamentou a Reforma da Instrução Pública, todos os alunos matriculados nas escolas públicas seriam considerados aspirantes a escoteiros. Para ser inscrito escoteiro eram necessários a idade mínima de 10 anos, a deliberação pessoal espontânea para a instrução e o consentimento dos pais por escrito. Os professores de ginástica das escolas normais e das escolas complementares seriam os instrutores do escotismo. As linhas de tiro destinavamse aos alunos maiores de 16 anos das escolas normais, ginásios ou escolas profissionais. 
A iniciativa, implementada em 1917, ganhou impulso com a obrigatoriedade da medida e pela sua generalização em todas as escolas públicas. O Regulamento para o Escotismo no Estado de São Paulo (Decreto 3.531, de 22/11/1922) buscou detalhar as normas para a organização e o funcionamento do escotismo escolar. Nesse sentido, o escotismo foi compreendido como "os exercícios, tanto quanto possível militares, para melhor desenvolvimento físico dos alunos e também o conhecimento das máximas cívicas para o seu aproveitamento moral". Estabelecia três categorias de escoteiros fortemente hierarquizadas: aspirantes, escoteiros e escoteiros de $1^{\text {a }}$ classe. Para passar de uma para outra classe era preciso prestar exames cujos programas eram organizados pela Diretoria Geral da Instrução Pública. Em relação aos direitos e deveres, previa-se para os escoteiros lugar reservado nas festas escolares e preferência para fazer a guarda da bandeira nacional; em contrapartida, exigia-se deles bom comportamento, aplicação, assiduidade, o conhecimento do Código dos Escoteiros e o seu cumprimento.

Quanto aos instrutores, procurou-se dar-Ihes um caráter mais profissional, exigindo para o exercício curso completo de escotismo e exame perante comissão de dois membros.

O escotismo configurava-se como uma associação escolar e civil. Por isso as comissões regionais filiadas à Associação Brasileira de Escoteiros eram centralizadas na Diretoria Geral de Instrução Pública, composta por um presidente e vice, um secretário e vice e um tesoureiro, todos membros da comunidade, além de um delegado técnico, designado pela Diretoria do Ensino, de preferência o diretor do grupo escolar ou um professor, e um instrutor. O regulamento indicava, ainda, critérios para a denominação das agremiações de escoteiros, de preferência o nome de um vulto da história pátria, especialmente um bandeirante, resgatando, dessa forma, a bravura e a determinação de personagens que marcaram a história do estado de São Paulo.

A prática do escotismo deveria ocorrer dentro e fora das escolas. As aulas de educação cívica, educação moral, ginástica e evoluções faziam parte do horário regulamentar, enquanto as matérias referentes ao escotismo propriamente seriam ministradas fora do horário das aulas.

O entusiasmo pelo escotismo foi grande no início da década de 1920. A ele se referiam os educadores como "magnífica escola de moral e civismo". Os profissionais da educação buscaram dar-lhe toda a ênfase possível e adaptá-lo aos hábitos e costumes paulistas. 
Participando das comemorações cívicas e da campanha em prol da erradicação do analfabetismo, os escoteiros escolares exerciam práticas peculiares de cidadania nas escolas primárias.

A imprensa pedagógica exerceu um papel relevante na difusão da prática do escotismo escolar. Os Anuários do Ensino dos anos 20 publicaram circulares, legislação pertinente e orientações específicas para a implementação do escotismo. O Anuário de 1920-1921 transcreve as conclusões e memórias apresentadas nas reuniões dos delegados de ensino realizadas na capital. Entre as teses defendidas pelos delegados encontra-se "sugestões para a educação moral e cívica dos alunos de curso primário e médio". A transcrição abaixo permite perceber as representações dos profissionais da educação, de conteúdo eminentemente nacionalista.

A primeira comissão, considerando que sobre $o$ assunto existe um trabalho completo do Professor G. Kuhlmann, resolveu sugerir:

$(\ldots)$

$2^{-}-$que se institua a "religião do civismo":

a- com o culto dos grandes brasileiros mortos ou vivos - colocando seus retratos nas classes dos grupos e escolas e tomando esses próhomens como patronos das referidas classes;

b- conhecimento de suas biografias e comemoração pelas respectivas classes, das datas que lembrem fatos de vida desses patronos;

c- a instituição do dia da Pátria para o seu culto;

d- o culto da Bandeira;

(..)

3-. propagar e instituir o escotismo como escola maravilhosa de educação moral e cívica (grifos meus);

(...)

5-- cuidar do ensino cívico, fazendo-o de toda a maneira, em todas as oportunidades, conjuntamente com as outras matérias, não dispensando, contudo, a adoção de um plano pre concebido que oriente o professor e dê finalidade do estudo. (Anuário do Ensino do Estado de São Paulo, 1920-1921, pp. 296-297) 
O Anuário do Ensino de 1923 consagrou inúmeras páginas ao relato dos delegados de ensino sobre a execução da reforma de 1920. Entre os dados apontados, todos os delegados mencionaram a adoção do escotismo, exaltando a iniciativa do governo estadual. A propósito, referiase o professor Plínio Braga:

\begin{abstract}
Escola admirável de educação física, moral e cívica, o escotismo mereceu de nós o maior carinho.

Não conhecemos, confessamos sinceramente, outra escola que melhores resultados possa produzir na formação do caracter dos nossos pequenos patrícios. Tudo o de que precisamos para infundir entre as crianças o amor à Pátria, à família, à escola, aos trabalhos, aos exercícios físicos, à solidariedade humana, em suma, o amor do que é belo, nobre e útil, nela encontramos. (p. 301)
\end{abstract}

Durante a década de 1920, a Revista Escolar publicou, sistematicamente, uma seção intitulada "Escotismo", incluindo artigos enfatizando a relevância do mesmo, sua relação com a educação moral e a educação cívica e instruções sobre os princípios do Manual dos Escoteiros, sobre como proceder perante a Bandeira e o Hino nacionais, marchas em colunas, exemplos de aula sobre polidez, entre outras orientações.

A apoteose desse movimento nacionalista ocorreu no ano de 1922 , por ocasião das comemorações do Centenário da Independência do Brasil. A Diretoria do Ensino do Estado de São Paulo buscou dar a esse evento toda a solenidade possível, recomendando que a comemoração fosse realizada em todos os estabelecimentos de ensino público do estado "a fim de que os festejos da independência nacional tenham verdadeiro cunho popular e assumam as proporções dignas do fato histórico relembrado" (Anuário do Ensino do Estado de São Paulo, 1922-23, p. 306). Mediante circular expedida às delegacias de ensino, a Diretoria prescreveu as partes do programa que obrigatoriamente deveriam constar nos festejos organizados pelas escolas, compreendendo o hasteamento da bandeira nacional e o canto de hinos patrióticos.

Seguindo as determinações da Diretoria, em todas as regiões de ensino foram realizadas concentrações preparatórias, nas quais se reuniram cerca de 100 mil escoteiros escolares. No dia da comemoração do 
Centenário, grupos de escoteiros da capital e do interior de São Paulo, reuniram-se nas proximidades do monumento do Ipiranga. $O$ jornal Correio Paulistano, de 8/9/1922, registrou o fato da seguinte forma:

\begin{abstract}
À esquerda do monumento, partilhando suave declive da montanha verde, um quadro de incomparável beleza e de uma significação profundamente profética sugeria aos olhos da multidão delirante de entusiasmo, toda a visão do Brasil de amanhã. Era o acampamento de escoteiros...
\end{abstract}

Instantes depois, marchavam, entre os aplausos delirantes, os rumores das palavras e os vivas frenéticos que reboavam, eletrizando a massa popular, e vinham colocar-se no local que Ihes estavam destinados.

Eram doze mil crianças. Cada uma, um Brasil pequenino. Todas, o Brasil imenso, simbolizado nelas, vivo nelas, presente em sua galhardia, na beleza infantil de seu porte. ${ }^{9}$

Participando das comemorações cívicas, os grupos de escoteiros recriavam o fascínio popular despertado pelos batalhões infantis no início do século $X X$. A militarização da infância ressurgia de forma mais sistematizada e racionalizada sob os auspícios dos órgãos da administração do ensino público e a Associação Brasileira de Escotismo. As práticas cívicomilitares em voga nas escolas primárias atendiam, assim, a múltiplos propósitos: fosse a perpetuação da memória histórica nacional, a exibição das virtudes morais e cívicas inscritas na obra formativa escolar, a ação educadora da escola para o conjunto da sociedade ou a expressão do imaginário sociopolítico da República.

A administração do ensino público preocupou-se em normalizar o máximo possível os aspectos formais do escotismo. Ainda em 1922, foi instituída uma flâmula para servir de distintivo de cada comissão regional. Nela deveria ser inscrito o nome do bandeirante escolhido para patrono dos escoteiros. Compreendia a flâmula um triângulo isósceles de $45 \mathrm{~cm}$ de base e $90 \mathrm{~cm}$ de altura. No círculo vermelho abaixo das iniciais E.P. (Escoteiro Paulista), deveria ser inscrito o nome da localidade a que pertencia a comissão. Na parte azul da flâmula, o nome do patrono e, abaixo, a data do maior feito do bandeirante (ibidem, p. 167). Em 1923, o diretor geral do ensino enviou aos delegados regionais uma circular com o seguinte teor: 
Deveis providenciar com o máximo interesse no sentido de ser intensificada a instrução dos escoteiros escolares, de acordo com o regulamento em vigor. É necessário que o movimento escotista do Estado de São Paulo tenha este ano grande desenvolvimento, afim de ficar perfeitamente consolidada a finalidade educativa que o escotismo assegura. (Anuário do Ensino do Estado de São Paulo, 1923, p. 588)

A nova reforma da instrução pública, em vigor a partir de 1925, retomou a estrutura anterior do ensino primário e omitiu qualquer referência ao escotismo. Porém, manteve o espírito nacionalista, introduzindo nas escolas públicas de São Paulo o Orfeão Infantil Paulista, composto por todos os alunos das duas seções dos grupos escolares dos terceiros e quartos anos. Tal atividade tinha por objetivo desenvolver nas crianças o gosto pelo canto e pela poesia nacional. Por isso, o Orfeão deveria adotar apenas músicas e poesias de autores brasileiros que deveriam ser executadas somente depois de aprovadas pela Diretoria Geral da Instrução Pública. Cada grupo escolar deveria ter o seu orfeão com o nome do estabelecimento e ser dirigido pelo inspetor especial de música. Os ensaios seriam realizados aos sábados com duração de 50 minutos.

No entanto, o escotismo continuou a ser praticado nas escolas públicas paulistas até meados do século $\mathrm{XX}$, sem o caráter de obrigatoriedade e a euforia que marcaram os anos 20.

Pelo Código da Educação de 1933 (Decreto 5.884, de 21/4/1933), o escotismo passou a ser compreendido como uma das instituições peri e extra-escolares. Para a sua organização, foi criada a Associação Escolar de Escoteiros, considerada auxiliar de educação física, moral e cívica, constituída de alunos das escolas públicas que, com mais de 11 anos, o quisessem e tivessem, para isso, o consentimento escrito dos pais, tutores ou responsáveis. A Associação Escolar de Escoteiros deveria filiar-se à Associação Brasileira de Escoteiros. A política estadual para o escotismo volta-se não mais para a obrigatoriedade padronizada, mas para o incentivo aos núcleos existentes ou que viessem a ser criados.

Além da assistência social, os grupos de escoteiros escolares deveriam desenvolver campanhas contra o analfabetismo nas zonas de população dispersa do interior, fazendo a distribuição de livros e impressos e difundir noções de higiene rural.

Em 1937, o estado de São Paulo cria a Corporação Escolar de Bandeirantes nos institutos e escolas profissionais. Nesse ano, o escotismo 
volta a subordinar-se à Diretoria de Ensino. Circular expedida aos delegados de ensino em 28/1/1937 exemplifica o teor das novas orientações: a orientação e a fiscalização do escotismo ficava a cargo dos delegados regionais por intermédio dos inspetores e diretores de estabelecimentos de ensino. Nos grupos escolares em que existisse o escotismo, este ficaria sob a responsabilidade do diretor do estabelecimento. Só deveriam ser criados núcleos de escoteiros onde houvesse condições materiais para esse fim e pessoas qualificadas (Anuário do Ensino do Estado de São Paulo, 1936-37, p. 320).

Nos anos 40, ainda é possível encontrar alguns poucos núcleos de escoteiros vinculados às escolas públicas. O esforço para a manutenção do escotismo escolar sobrevive mais pela iniciativa da Associação Brasileira de Escoteiros que pela ação do poder público. A educação moral e a educação cívica ganham novos sentidos após a Segunda Guerra Mundial e no contexto da democratização do país, encerrando, dessa maneira, um capítulo importante na história da educação e da cultura do país marcada pela educação militar.

As práticas de militarização da infância revelam mais uma das faces da configuração do currículo do ensino primário. Elas demonstram como as políticas de educação popular aliaram a educação moral e cívica às políticas do corpo. Civismo, patriotismo, nacionalização. Esses ideais expressam as tentativas inolvidáveis, porém nem sempre bem-sucedidas, de se transformarem as escolas primárias em agências de civilização das massas.

\section{Notas}

1. Trata-se do projeto intitulado "Lições da Escola Primária: Um estudo sobre a cultura escolar paulista (1892-1968)", realizado com o apoio do CNPq.

2. No período delimitado para esta pesquisa, os programas do ensino primário do estado de São Paulo foram reformulados em 1894, 1905, 1921, 1925 e 1946-47. A reformulação de 1925 vigorou por cerca de 25 anos.

3. Embora o parecer tenha sido apresentado ao parlamento em 12 de setembro de 1882, a publicação do extenso material ocorreu no ano de 1883. Ver Rui Barbosa, 1946 (Obras completas, v. X, Tomo II).

4. O princípio da educação integral foi disseminado na Europa e no continente americano no final do século XIX, fundamentado, especialmente, na obra de Spencer "Education: Intellectual, moral, physical".

5. Essas mesmas representações estão presentes nos pareceres exarados para o Congresso de Instrução do Rio de Janeiro em 1883. Ver Actas e Pareceres do Congresso da Instrucção do Rio de Janeiro, 1884. 
6. O mesmo ocorreu em Minas Gerais, onde os exercícios militares foram introduzidos nos programas do ensino primário em 1906. Para uma análise detalhada sobre a Educação Física e a instrução militar em Minas Gerais, ver Vago 1999.

7. Na França os exercícios militares e as linhas de tiro foram introduzidos nos planos de estudos das escolas normais e primárias no início da década de 1880. Uma lei de 1882 instituiu os Batalhões Escolares, considerados organizações necessárias para a República e armados com fuzis de fabricação específica para esse fim. Nouveau dictionnaire de pedagogie et d'instruction primaire, 1911.

8. O escotismo surgiu na Inglaterra por volta de 1907, por iniciativa do general Lord Robert Stephenson Smyth Baden-Powell, cujas bases foram lançadas no livro Scouting for Boys (1908). A experiência inglesa logo se espalhou pela Europa e pelos Estados Unidos. Foi introduzido no Brasil em 1910, na cidade do Rio de Janeiro, onde foi impulsionado por Olavo Bilac e Mário Cardin. A Associação Brasileira de Escoteiros foi criada em 1914. Em 1917, a Liga de Defesa Nacional reconheceu a Associação Brasileira de Escoteiros como sua filiada e como instituição nacional, entregando-Ihe a missão de centralizar todo o trabalho de escotismo no Brasil.

9. Artigo transcrito no Anuário do Ensino do Estado de São Paulo, 1922-1923, pp. 301-303

\section{The infancy militarism: Expressions of nationalism in the Brazilian culture}

ABSTRACT: The text comprehends one study about the practices of the infancy militarism, that is practices of patriotism nature, civil military practices that predominate during the primary education, in the beginning of $X X$ century. In this sense, it remarks the introduction of the discipline "military gymnastic and exercises" in the educational curriculum and its implications in the face of the infancy battalion formation. It also analyses the school scouts, the effervescent movement in São Paulo state during the 1910s and 1920s, identified as one expression of militarism and nationalism on the Brazilian education. Manuscript sources were found and used to carry out this investigation in the Estado de S. Paulo newspaper files and educational journals from that time.

\section{Bibliografia}

ANUÁRIOS do Ensino do Estado de São Paulo, 1907-1908; 1909-1910; 1911-1912; 1917, 1918, 1922-23, 1936-37.

BARBOSA, R. Reforma do Ensino Primário e várias instituições complementares da instrução pública. Rio de Janeiro: Ministério da Educação e Saúde, 1947, (Obras Completas, v. 10, t.1-4). 
BOTO, C.J.M.C. Rascunhos de Escola na Encruzilhada dos Tempos. Dissertação de mestrado em Educação. São Paulo, 1990.

CAMPOS, P.D. Estatutos e regulamentos. Associação Brasileira de Escoteiros. São Paulo: Typ. Pasquino, 1922. (Série Biblioteca do Escoteiro).

CERTEAU, M. A escrita da história. Rio de Janeiro: Forense Universitária, 1982.

CHARTIER, R. A história cultural: Entre práticas e representações. Lisboa: Difel, 1990.

. "Le monde comme représentation". Annales ESC. 1989, v. 6, pp. 1505-1520.

CHERVEL, A. "História das disciplinas escolares: Reflexões sobre um campo de pesquisa". Teoria \& Educação. Porto Alegre, 1990, v. 2.

COLEÇÃO de Leis e Decretos do Estado de São Paulo, 1890-1950.

FRAGO, A. V. "Historia de la educación e historia cultural: Posibilidades, problemas, cuestiones". Texto apresentado no II Congresso Iberoamericano de Educação Latino Americana, 1994. Mimeo.

GOODSON, I. A construção social do currículo. Lisboa: Educa, 1997.

. Currículo: Teoria e história. Petrópolis: Vozes, 1995.

HEBRARD, J. "A escolarização dos saberes elementares na época moderna". Teoria \& Educação. Porto Alegre, 1990, v. 2, pp. 65-110.

HOBSBAWM, E. e RANGER, T. A invenção das tradições. Rio de Janeiro: Paz e Terra, 1997.

JULIA, D. "La culture scolaire comme objet historique". In: Conferência de Encerramento do ISCHE, 15, Lisboa, 1993.

NAGLE, J. A educação e sociedade na Primeira República. São Paulo: EPU, 1974.

. "A educação na Primeira República". In: FAUSTO, B. História geral da civilização brasileira. Rio de Janeiro: Bertrand Brasil, 1990, T. III, v. 2, pp. 261- 291.

NÓVOA, A. História da Educação. Relatório apresentado à Faculdade de Ciências da Educação. Lisboa, 1994. Mimeo. 
POPKEWITZ, Th. "The study of curriculum history, social regulation and power in school". The Journal of Curriculum Studies. 1997, v. 29, ํo 2.

REVISTA DE EDUCAÇÃO. 1941-43, v. XXX; 1944, v. XXXII.

REVISTA DE ENSINO. Associação Beneficente do Professorado Paulista. São Paulo, 1902 e 1908, 1916, 1918.

REVISTA ESCOLAR. São Paulo, 1926, 1927.

SÃO PAULO. Programa de Ensino para as Escolas Primárias - Ato de 19/2/ 1925. Diretoria Geral da Instrução Pública. São Paulo: Imprensa Oficial, 1932.

SOUZA, R.F. Templos de civilização: A implantação da escola primária graduada no estado de São Paulo (1890-1910). São Paulo: Editora da Unesp, 1998.

SPENCER, H. Educação: intellectual, moral e physica. Porto: Casa Editora Alcino Aranha \& Cia., 1884.

VAGO, T.M. Cultura Escolar, Cultivo de Corpos. Educação Physica e Gymnastica como práticas constitutivas dos corpos de crianças no ensino público primário de Belo Horizonte (1906-1920). Tese de doutorado em Educação, Universidade de São Paulo, São Paulo, 1999. 